\title{
Liposome-mediated transfection of wild-type P53 DNA into human prostate cancer cells is improved by low-frequency ultrasound combined with microbubbles
}

\author{
WEN-KUN BAI, WEI ZHANG, BING HU and TAO YING \\ Department of Ultrasound in Medicine, Shanghai Institute of Ultrasound in Medicine, \\ Sixth People's Hospital Affiliated to Shanghai Jiao Tong University, Shanghai 200233, P.R. China
}

Received March 11, 2015; Accepted March 24, 2016

DOI: $10.3892 / \mathrm{ol} .2016 .4477$

\begin{abstract}
Prostate cancer is a common type of cancer in elderly men. The aim of the present study was to evaluate the effects of ultrasound exposure in combination with SonoVue microbubbles on liposome-mediated transfection of wild-type P53 genes into human prostate cancer cells. PC-3 human prostate cancer cells were exposed to ultrasound; duty cycle was controlled at $20 \%$ ( $2 \mathrm{sec}$ on, $8 \mathrm{sec}$ off) for 5 min with and without SonoVue microbubble echo-contrast agent using a digital sonifier (frequency, $21 \mathrm{kHz}$; intensity, $46 \mathrm{~mW} / \mathrm{cm}^{2}$ ). The cells were divided into eight groups, as follows: Group A (SonoVue + wild-type P53), group B (ultrasound + wild-type P53), group C (SonoVue + ultrasound + wild-type P53), group D (liposome + wild-type P53), group E (liposome + SonoVue + wild-type P53), group F (liposome + wild-type P53 + ultrasound), group G (liposome + wild-type P53 + ultrasound + SonoVue) and the control group (wild-type P53). Following treatment, a hemocytometer was used to measure cell lysis, reverse transcription-quantitative polymerase chain reaction and western blotting were performed to detect P53 gene transfection efficiency, Cell Counting Kit-8 was employed to reveal cell proliferation and Annexin V/propidium iodide staining was used to determine cell apoptosis. Cell lysis was minimal in each group. Wild-type P53 gene and protein expression were significantly increased in the PC-3 cells in group $\mathrm{G}$ compared with the control and all other groups $(\mathrm{P}<0.01)$. Cell proliferation was significantly suppressed in group $\mathrm{G}$ compared with the control group and all other
\end{abstract}

Correspondence to: Professor Bing $\mathrm{Hu}$ or Professor Tao Ying, Department of Ultrasound in Medicine, Shanghai Institute of Ultrasound in Medicine, Sixth People's Hospital Affiliated to Shanghai Jiaotong University, 600 Yishan Road, Shanghai 200233, P.R. China

E-mail: ultrasound505@163.com

E-mail: taoying202@163.com

Key words: low-frequency ultrasound, low-energy ultrasound, liposome, microbubble, wild-type P53, gene therapy groups $(\mathrm{P}<0.01)$. Cell apoptosis levels in group $\mathrm{G}$ were significantly improved compared with the control group and all other groups $(\mathrm{P}<0.01)$. Thus, the results of the present study indicate that the use of low-frequency and low-energy ultrasound in combination with SonoVue microbubbles may be a potent physical method for increasing liposome gene delivery efficiency.

\section{Introduction}

Prostate cancer is the second most frequently diagnosed cancer in men worldwide, with 1.1 million new cases estimated to have occurred in 2012 (1). Progression into the androgen-independent stage of prostate cancer is considered to be primarily due to resistance to apoptosis, and is accompanied by increased proliferation and survival of cells within the primary or metastatic tumors (2). At present, there are no effective therapies available for curing or controlling the androgen-independent stage of prostate cancer, due to the high rate of apoptosis resistance. The primary therapeutic modalities used to treat prostate cancer are surgery, radiation and hormone therapy $(3,4)$. These modalities have been demonstrated to have certain curative effects on early-stage prostate cancer; however, they have various limitations, including injury to the surrounding normal tissues, drug resistance and tumor recurrence (4-6).

Gene therapy is a promising method for the treatment of human diseases. Among the numerous types of anticancer treatment, gene therapy has gained attention in clinical trials, as it has low side-effects compared with chemotherapy and radiotherapy (7). Several methods have been developed for the delivery of DNA into cells, including chemically facilitated, vector-mediated, mechanical (8) and electric pulse (9) transfection. In the current clinical protocols for gene therapy, virus-derived and non-virus-derived vectors are primarily used to deliver DNA into cells (10). Although viral vectors have high transfection efficiencies over a wide range of cell targets, major limitations have occurred during clinical trials, such as the induction of the immune response to viruses and insertional mutagenesis (11). These unwanted side-effects have increased support for the use of non-viral methods of gene transfer. Non-viral vectors, such 
as liposomes, are a promising alternative to viral vectors, as they are safe, versatile, easy to prepare and simple to scale up. However, non-viral vectors generally have low transfection efficiencies $(12,13)$.

The P53 protein is a tumor suppressor that has a regulatory function associated with cell apoptosis. Furthermore, the P53 gene is the most commonly mutated gene in a large proportion of human cancer types. Therefore, the introduction of wild-type P53 into tumors may be a novel strategy for treating cancer, by inducing apoptotic death in cancer cells. As loss of P53 function is common in prostate cancer (14), restoring P53 activity is an attractive target for prostate cancer gene therapy (15).

Several previous reports (16-18) have described the combined use of sonoporation and microbubbles to achieve delivery of naked plasmid DNA into cancer cells in tissue culture-based systems. Sonoporation is an emerging and promising physical method for cancer gene therapy that typically operates at a frequency of 1-35 MHz, and has several advantages over other nonphysical methods of nucleic acid delivery; for example, sonoporation also has the ability to deliver drugs or small molecules (19). However, the transfer efficiency depends on ultrasound frequency, intensity (20) and the number of microbubbles (21). Transfer efficiency increases with increasing ultrasound energy while the frequency decreases (22). The presence of microbubbles can also improve transfection efficiency (23). However, due to the high energy involved in ultrasound treatment, cell lysis frequently occurs and possibly masks other effects on the surviving cells (24).

Our previous study identified that low-frequency and low-energy ultrasound combined with microbubbles improved liposome-mediated transfection of pEGFP DNA into human prostate cancer cells. Our previous study also demonstrated that low-frequency and low-energy ultrasound combined with microbubbles could induce cell membrane damage but resulted in minimum cell death. Thus, we proposed that the rapid collapse of microbubbles during sonoporation has major role in gene delivery into cells (25).

The present study evaluated the improvement of liposome-mediated transfection of wild-type P53 DNA into human prostate cancer cells by using low-frequency and low-energy ultrasound combined with SonoVue microbubbles. The aim of the study was to develop a novel gene therapy technique that may be used to treat androgen-independent prostate cancer.

\section{Materials and methods}

Cell culture. A human androgen-independent prostate cancer cell line, PC-3 (null P53), was obtained from the Cell Bank of Type Culture Collection of Chinese Academy of Sciences (Shanghai, China). The cells were grown in Dulbecco's modified Eagle medium (Gibco; Thermo Fisher Scientific, Inc., Waltham, MA, USA) supplemented with $10 \%$ heat-inactivated fetal bovine serum (Invitrogen; Thermo Fisher Scientific, Inc.) at $37^{\circ} \mathrm{C}$ in humidified air with $5 \% \mathrm{CO}_{2}$. PC-3 cells were counted under an optical microscope (Olympus CX23; Olympus, Tokyo, Japan) using a hemocytometer (Qiujing XB-K-25; Shanghai Qiujing Biochemical Reagent and Instrument
Co., Ltd., Shanghai, China) and resuspended at a density of $1 \times 10^{5}$ cells $/ \mathrm{ml}$. The cells were transferred into polystyrene test tubes ( $1 \mathrm{ml}$ cells/tube; Weierkang Medical Supplies Co., Ltd., Taizhou, China) with diameters of $13 \mathrm{~mm}$. Polystyrene test tubes and a Mylab90 ultrasound imaging system (Esaote, Genoa, Italy) were used, which did not absorb sound waves. If the sound wave was absorbed, it would make the sound energy decay. Exposure to ultrasound resulted in no significant effect on the acoustic permeation ratio. The bottom of the tube was planar, which allowed it to more closely contact the ultrasound probe.

Ultrasound apparatus and microbubbles. A low-frequency ultrasonic therapy machine (Shanghai Institute of Ultrasound in Medicine, Shanghai, China) and a microbubble echo-contrast agent (SonoVue; Bracco, Milan, Italy) were used to perform gene transfection. Ultrasound was generated using a $21-\mathrm{kHz}$ ultrasound probe covered with (Shuangyi Medical Equipment Co., Tianjin, China) transmission gel and the spatial average temporal average intensity was $46 \mathrm{~mW} / \mathrm{cm}^{2}$. The duty cycle was controlled at $20 \%$ ( $2 \mathrm{sec}$ on, $8 \mathrm{sec}$ off) for $5 \mathrm{~min}$. The diameter of the ultrasound probe was $13 \mathrm{~mm}$, which was the same as the diameter of the test tube. In all of the experiments, a clamp was attached to a metal stud to keep the transducer facing directly upward (25).

Upon use, SonoVue was reconstituted in $5 \mathrm{ml}$ phosphate-buffered saline (PBS) that was $2-5 \mu \mathrm{m}$ in diameter.

Preparation of plasmid DNA. Wild-type P53 plasmid DNA (donated by the Center Laboratory of Sixth People's Hospital Affiliated to Shanghai Jiao Tong University) was prepared using an EZNA Plasmid Miniprep kit II (Omega Bio-Tek, Inc., Norcross, GA, USA). Wild-type P53 plasmid DNA was identified by two restriction sites; enzyme digestion (SalI or XhoI; Fermentas; Thermo Fisher Scientific, Inc.) was performed, followed by electrophoresis. Briefly, the amplified P53 DNA fragment was purified from the corresponding band in the agarose gel and incubated with $\mathrm{SalI} / \mathrm{XhoI}$ at $37^{\circ} \mathrm{C}$ for $2 \mathrm{~h}$. Next, digestion products were purified from the corresponding band in the agarose gel. The processed P53 fragment was then cloned into EZNA using T4 DNA ligase (Thermo Fisher Scientific, Inc.). The recombinant plasmid was transformed into DH5 $\alpha$ (Beyotime Institute of Biotechnology, Nanjing, China) and confirmed by PCR of the bacterial solution and enzymatic digestion.

Cell lysis. PC-3 cells were divided into four groups, as follows: The control group, the SonoVue alone group, the ultrasound alone group and the ultrasound combined with SonoVue group. Prior to ultrasound irradiation, $200 \mu 1$ SonoVue was added to each SonoVue alone and ultrasound combined with SonoVue group test tube. Immediately after exposure to ultrasound, the cell numbers were counted under an optical microscope (x200 magnification; 4 images/group; Olympus CX23; Olympus) using a hemocytometer (Qiujing XB-K-25; Shanghai Qiujing Biochemical Reagent and Instrument Co., Ltd.). Cell lysis was measured using the following formula: Cell lysis $(\%)=[1$ - (number of viable cells per image following therapy / total number of cells per image prior to therapy)] x 100 . 
Gene transfer. Transfection was performed using a Lipofectamine 2000 kit (Invitrogen; Thermo Fisher Scientific, Inc.), according to the manufacturer's protocol, at a plasmid:liposome (Invitrogen; Thermo Fisher Scientific, Inc.) ratio of 1:2. Prior to ultrasound irradiation, these transfection reagents were added to the suspension of PC-3 cells in each sample. PC-3 cells were resuspended in polystyrene sample test tubes at a density of $1 \times 10^{5}$ cells $/ \mathrm{ml}$ and divided into eight groups, as follows: Group A (SonoVue + wild-type P53), group B (ultrasound + wild-type P53), group C (SonoVue + ultrasound + wild-type P53), group D (liposome + wild-type P53), group E (liposome +SonoVue + wild-type P53), group F (liposome + wild-type P53+ultrasound), group G (liposome + wild-type P53 + ultrasound + SonoVue) and the control group (wild-type P53). In groups A, C, E and G, $200 \mu \mathrm{l}$ SonoVue was added to each tube. Following ultrasound exposure, the cell suspensions were transferred onto 12 -well plates.

Reverse transcription-quantitative polymerase chain reaction (RT-qPCR). Wild-type P53 mRNA expression was examined by RT-qPCR. Total cellular RNA was extracted from frozen tumor tissues using the RNAiso Plus kit (Takara Biotechnology, Co., Ltd., Dalian, China), according to the manufacturer's protocol, and purified using cold $75 \%$ ethanol precipitation. A DNase step was performed using a PrimeScript ${ }^{\mathrm{TM}}$ RT reagent kit with gDNA Eraser (Takara Biotechnology, Co., Ltd.). RNA concentration and quality were measured using the NanoDrop ND-1000 spectrophotometer (Thermo Fisher Scientific, Inc.). A volume of $5 \mu \mathrm{l}$ of purified RNA was used as the template for cDNA synthesis in the presence of $15 \mu \mathrm{l}$ of $5 \mathrm{X}$ RT buffer, $1 \mu \mathrm{l}$ random primer $(100 \mathrm{pmol} / \mu \mathrm{l}), 1 \mu \mathrm{l}$ reverse transcriptase and $8 \mu 1$ RNAse-free water, all purchased from Takara Biotechnology Co., Ltd. The reverse transcriptase was incubated at $25^{\circ} \mathrm{C}$ for $10 \mathrm{~min}, 60^{\circ} \mathrm{C}$ for $10 \mathrm{~min}$ and $70^{\circ} \mathrm{C}$ for $10 \mathrm{~min}$. The subsequent PCR mixture $(50 \mu \mathrm{l})$ consisted of $1 \mu \mathrm{l} \mathrm{cDNA}$, $25 \mu \mathrm{l}$ of $2 \mathrm{X}$ PCR buffer, $0.6 \mu \mathrm{l}$ of each primer $(25 \mathrm{pmol} / \mu \mathrm{l})$ and $22.8 \mu 1$ RNAse-free water, all purchased from Takara Biotechnology Co., Ltd. The primers used (Takara Biotechnology Co., Ltd.) were as follows: P53 forward, 5'-GACAGC CAAGTCTGTGACTTG-3' and reverse, 5'-CGCTATCTG AGCAGCGCTCATG-3'; and glyceraldehyde 3-phosphate dehydrogenase, forward 5'-TGACAACAGCCTCAAGATCAT C-3' and reverse, 5'-AGAGGCAGGGATGATGTTCTGG-3'. Amplification was performed for 1 cycle at $95^{\circ} \mathrm{C}$ for $3 \mathrm{~min}$, followed by 40 cycles at $95^{\circ} \mathrm{C}$ for $10 \mathrm{sec}$ and $60^{\circ} \mathrm{C}$ for $10 \mathrm{sec}$. The cycle fluorescence intensity generated using SYBR Green Master mix (Takara Biotechnology, Co., Ltd.) was recorded for each sample across 5 repeats using an ABI PRISM ${ }^{\circledR} 7500$ Sequence Detection System (Thermo Fisher Scientific, Inc.), and the mean fluorescence intensity was calculated and statistically analyzed. The relative expression of each gene was calculated and normalized using the $2^{-\Delta \Delta \mathrm{Cq}}$ method (26).

Western blot analysis. The protein expression of wild-type P53 was examined by western blotting $24 \mathrm{~h}$ after the PC-3 cells were transfected with wild-type P53, as previously described (27). Briefly, the cell line was solubilized in cold radioimmunoprecipitation assay lysis buffer (Beyotime Institute of Biotechnology). The proteins were separated using 12\% sodium dodecyl sulfate polyacrylamide gel electrophoresis and transferred onto a polyvinylidene difluoride membrane (Thermo Fisher Scientific Inc.). The membrane was incubated with PBS containing 5\% milk at room temperature for $2 \mathrm{~h}$. Next, the membrane was incubated with Tris-buffered saline with $0.1 \%$ Tween 20 containing $5 \%$ milk and mouse anti-human P53 (catalog no. ab1101; dilution, 1:1,000; Abcam, Cambridge, UK) or $\beta$-actin (catalog no. ab8226; dilution, 1:500; Abcam) monoclonal antibodies overnight at $4^{\circ} \mathrm{C}$. Following the incubation, the membrane was incubated again with horseradish peroxidase-conjugated goat anti-mouse secondary antibody (catalog no. ab6789; dilution, 1:2,000; Abcam) at room temperature for $1 \mathrm{~h}$. An enhanced chemiluminescence kit (Beyotime Institute of Biotechnology) was used to perform chemiluminescence detection. The relative protein expression was analyzed by Image-Pro ${ }^{\circledR}$ Plus software version 6.0 (Media Cybernetics, Inc., Rockville, MD, USA), represented as the density ratio vs. $\beta$-actin.

Cell proliferation. Immediately after gene transfection, each group of cells was seeded at $3 \times 10^{3}$ cells/well in 96-well plates. After 24 h, $100 \mu$ l Cell Counting Kit-8 (Dojindo Laboratories, Kumamoto, Japan) was added and the plates were incubated for $3 \mathrm{~h}$. The optical density for each well was measured using a microculture plate reader (FL600; Bio-Tek, Winooski, VT, USA) at a wavelength of $450 \mathrm{~nm}$ (28).

Cell apoptosis. Following ultrasound treatment, each group of cells was incubated for an additional $24 \mathrm{~h}$ in 6 -well plates. The cells were evaluated for apoptosis using a fluorescein isothiocyanate (FITC)-labeled Annexin V and propidium iodide (PI) double staining kit (Becton Dickinson, Franklin Lakes, NJ, USA), as previously described (29). After the 24-h incubation, cells were harvested, washed twice with PBS and resuspended with $0.5 \mathrm{ml} \mathrm{PBS}$ at a cell density of $1 \times 10^{6}$ cells $/ \mathrm{ml}$. Annexin V $(5 \mu \mathrm{l})$ and PI $(10 \mu \mathrm{l})$ were added to the wells in the dark. After 10 min incubation, the cells were analyzed by flow cytometry (BD FACSCalibur; Becton Dickinson) to determine the levels of apoptosis. Annexin V-FITC(+)/PI(-) cells were considered early apoptotic cells, while cells that were Annexin V-FITC(+)/PI(+) were considered late apoptotic cells. Therefore, the total apoptotic cell count equaled the sum of the Annexin-V-FITC(+)/PI(-) and the Annexin-V-FITC(+)/PI(+) cells (30).

Statistical analysis. Data are expressed as mean \pm standard deviation. SPSS software (version 13.0; SPSS, Inc., Chicago, IL, USA) was used to perform analysis of variance and t-tests to determine differences among the groups. A least significant difference post-hoc test was also performed. $\mathrm{P}<0.05$ was considered to indicate a statistically significant difference. Experiments were repeated three times.

\section{Results}

Detection of cell lysis. Cell lysis analysis is presented in Fig. 1. To assess cell lysis, the cells were examined immediately after ultrasound exposure. The ultrasound group and the ultrasound combined with SonoVue group exhibited significantly greater cell lysis compared the control group and the SonoVue alone group $(\mathrm{P}<0.001)$. Furthermore, significantly higher levels of 
Table I. Wild-type P53 transfection efficiency of PC-3 cells in groups A-G and the control group following gene transfection.

\begin{tabular}{lcc}
\hline \multirow{2}{*}{ Group } & \multicolumn{2}{c}{ Relative wild-type P53 expression } \\
\cline { 2 - 3 } & mRNA & Protein \\
\hline Control & Null & Null \\
A & Null & Null \\
B & $0.16 \pm 0.01$ & $0.24 \pm 0.04$ \\
C & $0.75 \pm 0.10^{\mathrm{a}}$ & $0.42 \pm 0.05^{\mathrm{a}}$ \\
D & $1.49 \pm 0.14^{\mathrm{a}, \mathrm{b}}$ & $0.60 \pm 0.05^{\mathrm{a}, \mathrm{b}}$ \\
E & $1.74 \pm 0.17^{\mathrm{a}, \mathrm{b}}$ & $0.66 \pm 0.03^{\mathrm{a}, \mathrm{b}}$ \\
F & $2.80 \pm 0.19^{\mathrm{a}-\mathrm{d}}$ & $0.77 \pm 0.03^{\mathrm{a}-\mathrm{d}}$ \\
G & $4.00 \pm 0.51^{\mathrm{a}-\mathrm{e}}$ & $0.87 \pm 0.02^{\mathrm{a}-\mathrm{e}}$ \\
\hline
\end{tabular}

Data are presented as mean \pm standard deviation. ${ }^{\mathrm{a}} \mathrm{P}<0.001 \mathrm{vs}$. control group; ${ }^{b} \mathrm{P}<0.001$ vs. group $\mathrm{C}$; ${ }^{\mathrm{c}} \mathrm{P}<0.001$ vs. group $\mathrm{D}$; ${ }^{\mathrm{d}} \mathrm{P}<0.001$ vs. group $\mathrm{E} ;{ }^{\mathrm{e}} \mathrm{P}<0.001$ vs. group $\mathrm{F}$.

Table II. Apoptosis of PC-3 cells in groups A-G and the control group following gene transfection.

\begin{tabular}{lc}
\hline Group & Apoptosis, $\%$ \\
\hline Control & $0.37 \pm 0.05$ \\
A & $0.48 \pm 0.05$ \\
B & $4.10 \pm 0.26^{\mathrm{a}, \mathrm{b}}$ \\
C & $5.78 \pm 0.35^{\mathrm{a}-\mathrm{c}}$ \\
D & $6.81 \pm 0.25^{\mathrm{a}-\mathrm{d}}$ \\
E & $6.91 \pm 0.24^{\mathrm{a}-\mathrm{d}}$ \\
F & $12.69 \pm 0.72^{\mathrm{a}-\mathrm{f}}$ \\
G & $21.23 \pm 1.58^{\mathrm{a}-\mathrm{g}}$ \\
\hline
\end{tabular}

Data are presented as mean \pm standard deviation. ${ }^{\mathrm{a}} \mathrm{P}<0.001$ vs. control group; ${ }^{b} \mathrm{P}<0.001$ vs. group $\mathrm{A} ;{ }^{\mathrm{c}} \mathrm{P}<0.001$ vs. group $\mathrm{B}$; ${ }^{\mathrm{d}} \mathrm{P}<0.001$ vs. group $\mathrm{C} ;{ }^{e} \mathrm{P}<0.001$ vs. group $\mathrm{D}$; ${ }^{\mathrm{f}} \mathrm{P}<0.001$ vs. group $\mathrm{E}$; ${ }^{\mathrm{g}} \mathrm{P}<0.001$ vs. group $\mathrm{F}$.

cell lysis were observed in the ultrasound combined with SonoVue group compared with the ultrasound group. There was no significant difference between the control group and the SonoVue alone group $(\mathrm{P}=0.945)$.

Detection of gene transfection efficiency. The results for gene transfection efficiency, as determined by RT-qPCR and western blotting, are presented in Table I and Fig. 2.

In group G (liposome + wild-type P53 + ultrasound + SonoVue), RT-qPCR and western blotting revealed obvious P53 mRNA and protein expression, respectively, in the PC-3 cells transfected with wild-type P53, while all other cell groups exhibited significantly lower expression levels $(\mathrm{P}<0.001)$.

Measurement of cell proliferation. Cell proliferation levels in group $\mathrm{G}$ was significantly suppressed relative to the control group $(\mathrm{P}<0.001)$. Furthermore, the suppression observed in

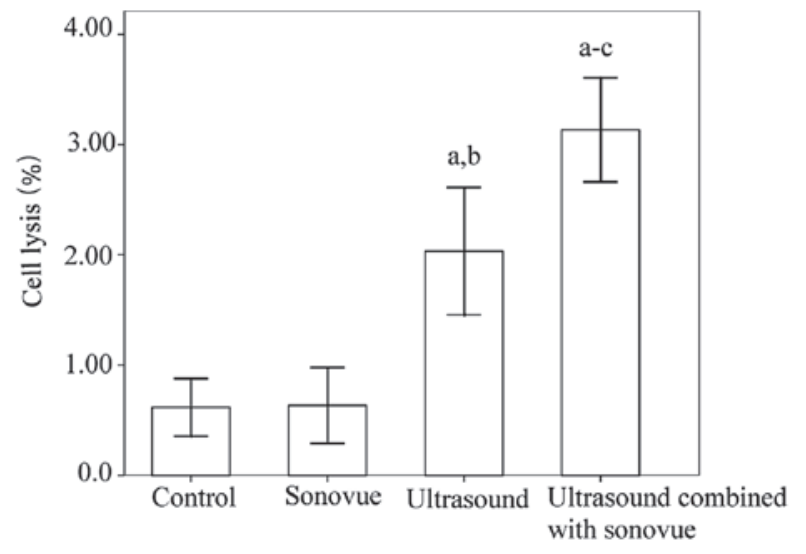

Figure 1. Cell lysis following exposure to ultrasound and/or microbubbles. ${ }^{\mathrm{a}} \mathrm{P}<0.001$ vs. control group; ${ }^{\mathrm{b}} \mathrm{P}<0.001$ vs. SonoVue group; ${ }^{\mathrm{C}} \mathrm{P}<0.001$ vs. ultrasound group.

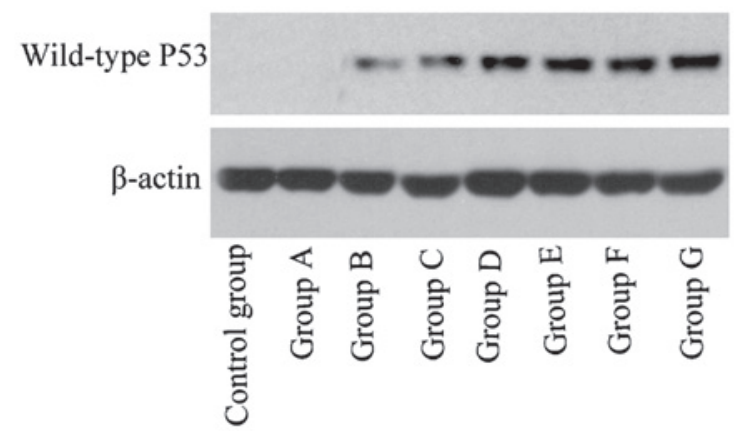

Figure 2. Western blot revealing wild-type P53 protein expression in groups $\mathrm{A}-\mathrm{G}$ and the control group $24 \mathrm{~h}$ after gene transfection.

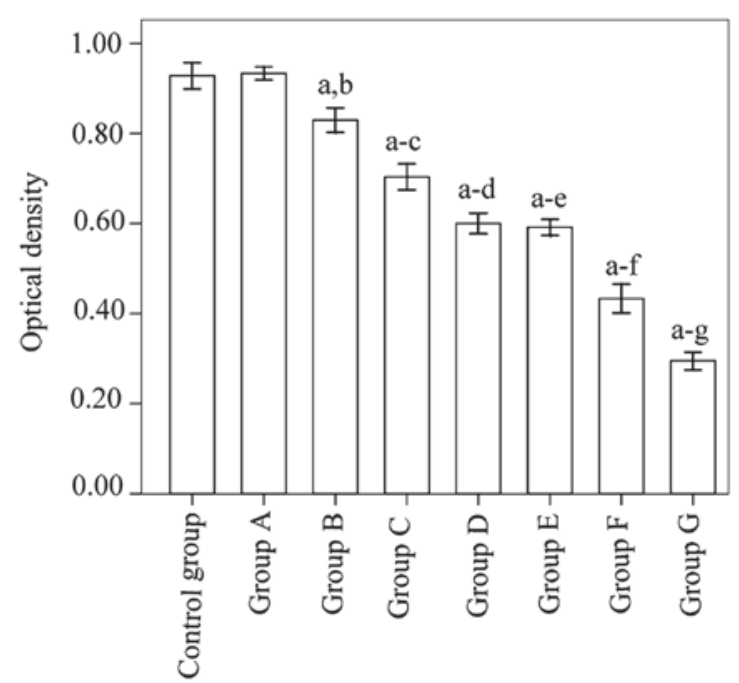

Figure 3. Cell proliferation in groups $A-G$ and the control group $24 \mathrm{~h}$ after gene transfection. ${ }^{\mathrm{a}} \mathrm{P}<0.001$ vs. control group; ${ }^{\mathrm{b}} \mathrm{P}<0.001$ vs. group $\mathrm{A}$; ${ }^{\mathrm{c}} \mathrm{P}<0.001$ vs. group $\mathrm{B} ;{ }^{d} \mathrm{P}<0.001$ vs. group $\mathrm{C} ;{ }^{\mathrm{e}} \mathrm{P}<0.001$ vs. group $\mathrm{D}$; ${ }^{\mathrm{f}} \mathrm{P}<0.001$ vs. group $\mathrm{E}$; ${ }^{\text {g }}<0.001$ vs. group $\mathrm{F}$.

group $\mathrm{G}$ was significantly greater than in any of the other groups $(\mathrm{P}<0.001)$ (Fig. 3).

Detection of cell apoptosis. Cell apoptosis levels in group G were significantly increased relative to the control group 

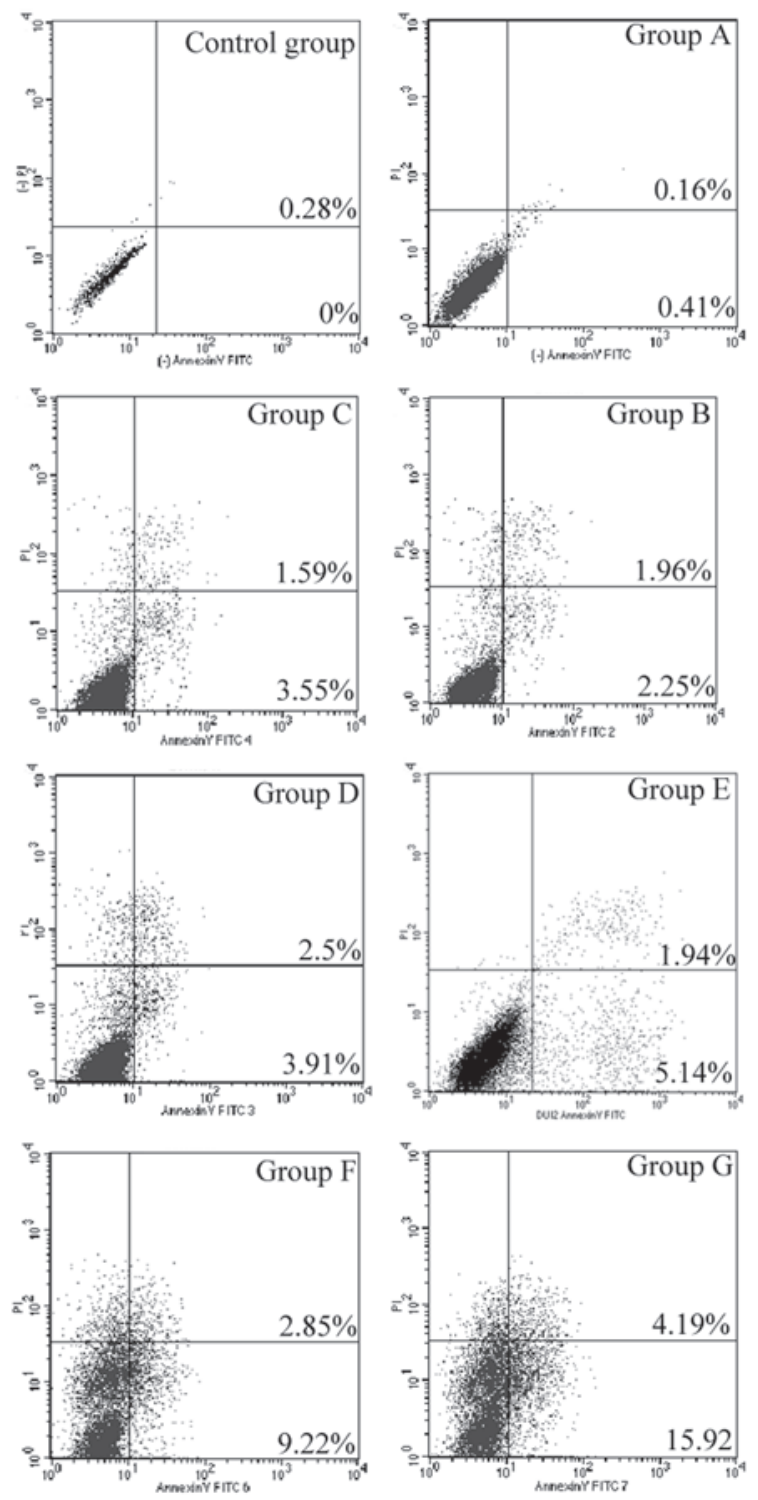

Figure 4. Flow cytometry analysis of cell apoptosis in groups A-G and the control group $24 \mathrm{~h}$ after gene transfection. PI, propidium iodide; FITC, fluorescein isothiocyanate.

$(\mathrm{P}<0.001)$. In addition, the proportion of cell apoptosis in group $\mathrm{G}$ was significantly greater than in all the other groups $(\mathrm{P}<0.001)$ (Fig. 4; Table II).

\section{Discussion}

The PC-3 cell line was selected for use in the current study, as it is a human androgen-independent prostate cancer cell line that does not express P53 (wild-type or mutant). Therefore, if wild-type P53 is detected in this cell line it must be due to successful transfection (28).

In the present study, ultrasound significantly combined with microbubbles improved wild-type P53 transfection efficiency of liposomes, and the efficiency was greater in group $\mathrm{G}$ compared with in groups A, B, C, D, E and F, and the control group. Thus, gene transfection was improved by increasing cell permeabilization using microbubbles and ultrasound to deliver molecules into the cytoplasm. Collapsing microbubbles and cavitation bubbles created by this collapse generate impulsive pressures, including liquid jets and shockwaves, that may damage cell membranes and cause transient membrane permeability, allowing exogenous molecules to enter into cells. The impulsive pressures can affect neighboring cells, as the shockwave propagation distance from the center of a cavitation bubble is considerably larger than the maximum radius of the cavitation bubble (31). Our previous study demonstrated that low-frequency and low-energy ultrasound combined with microbubbles could induce cell membrane damage. In addition, our previous study used transmission electron microscopy to detect cell membrane discontinuity and observed gaps in the cell membranes following ultrasound exposure (25). The results indicated that low-frequency and low-energy ultrasound may induce cell membrane damage to improve gene delivery.

In the present study, transfection with wild-type P53 suppressed PC-3 cell proliferation and increased apoptosis. Loss of normal P53 function and/or defects in the P53 signaling pathway, caused by missense mutations or deletions, occur in $>50 \%$ of types of human cancer, including prostate cancer. The P53 protein is a tumor suppressor gene product that can induce apoptosis, therefore, these molecular alterations are associated with resistance to cell death (32). Loss of P53 function as a result of mutation or deletion in the P53 gene occurs in 24\% of primary prostate tumors (33). Considering the aforementioned functions of P53 expression, the possibility of reactivating the P53 pathway has been extensively investigated in several types of cancer (34).

In previous studies, ultrasound frequencies of $1-3 \mathrm{MHz}$ have been used $(11,35)$. However, the present study used low-frequency $(21 \mathrm{kHz})$ and low-energy ultrasound, which is associate with easy penetration of the organism, less tissue absorption and reduced tissue injury. Low-frequency ultrasound predominantly induces mechanical and cavitation effects, and the temperature increase through the thermal effect is virtually negligible (36). The results of the present study demonstrated that low-frequency and low-energy ultrasound combined with microbubbles minimally induced the lysis of PC-3 cells. Cell lysis $<5 \%$ was considered as minimal damage. Considering these advantages, low-frequency and low-energy ultrasound shows promise for future use in cancer therapy.

In conclusion, the present study demonstrated that sonoporation, in the presence of microbubbles, was a promising technique for improving liposome transfer of wild-type P53 genes into prostate cancer cells and provided an experimental model for clinical gene therapy. Additionally, liposome-mediated transfection combined with low-frequency and low-energy ultrasound to induce the destruction of microbubbles was revealed as a feasible and efficient method for wild-type P53 delivery into prostate cancer cells. Although the exact mechanisms underlying efficient gene transfection remain to be elucidated, the rapid collapse of microbubbles during sonoporation is considered to have a major role in gene delivery into cells.

\section{Acknowledgements}

The present study was supported by the National Natural Science Foundation of China (grant nos. 81271597 and 81401421). 


\section{References}

1. Torre LA, Bray F, Siegel RL, Ferlay J, Lortet-Tieulent J and Jemal A: Global cancer statistics, 2012. CA Cancer J Clin 65 : 87-108, 2015

2. Xu AH, Hu ZM, Qu JB, Liu SM, Syed AK, Yuan HQ and Lou HX: Cyclic bisbibenzyls induce growth arrest and apoptosis of human prostate cancer PC3 cells. Acta Pharmacol Sin 31: 609-615, 2010

3. Mangar SA, Huddart RA, Parker CC, Dearnaley DP, Khoo VS and Horwich A: Technological advances in radiotherapy for the treatment of localised prostate cancer. Eur J Cancer 41: 908-921, 2005.

4. Tanaka G, Hirata Y, Goldenberg SL, Bruchovsky N and Aihara K: Mathematical modelling of prostate cancer growth and its application to hormone therapy. Philos Trans A Math Phys Eng Sci 368: 5029-5044, 2010.

5. Lecornet E, Ahmed HU, Moore C and Emberton M: Focal therapy for prostate cancer: A potential strategy to address the problem of overtreatment. Arch Esp Urol 63: 845-852, 2010.

6. Baumert H: Salvage treatments for prostatic radiation failure. Cancer Radiother 14: 442-445, 2010 (In French).

7. Verma IM and Somia N: Gene therapy-promises, problems and prospects. Nature 389: 239-242, 1997.

8. Wyber JA, Andrews J and D'Emanuele A: The use of sonication for the efficient delivery of plasmid DNA into cells. Pharm Res 14: 750-756, 1997.

9. Whelan J: Electroporation and ultrasound for gene and drug delivery. Drug Delivery Today 11: 585-586, 2002.

10. Danialou G, Comtois AS, Dudley RW, Nalbantoglu J, Gilbert R, Karpati G, Jones DH and Petrof BJ: Ultrasound increase plasmid-mediated gene transfer to dystrophic muscles without collateral damage. Mol Ther 5: 687-693, 2002.

11. Negishi Y, Omata D, Iijima H, Takabayashi Y, Suzuki K, Endo Y, Suzuki R, Maruyama K, Nomizu M and Aramaki Y: Enhanced laminin-derived peptide AG73-mediated liposomal gene transfer by bubble liposomes and ultrasound. Mol Pharm 7: 217-226, 2010

12. Audouy SA, de Leij LF, Hoekstra D and Molema G: In vivo characteristics of cationic liposomes as delivery vectors for gene therapy. Pharm Res 19: 1599-1605, 2002.

13. Hirko A, Tang F and Hughes JA: Cationic lipid vectors for plasmid DNA delivery. Curr Med Chem 10: 1185-1193, 2003.

14. Lin VC, Huang CY, Lee YC, Yu CC, Chang TY, Lu TL, Huang SP and Bao BY: Genetic variations in TP53 binding sites are predictors of clinical outcomes in prostate cancer patients. Arch Toxicol 88: 901-911, 2014.

15. Han L, Zhao J, Liu J, Duan XL, Li LH, Wei XF, Wei Y and Liang XJ: A universal gene carrier platform for treatment of human prostatic carcinoma by p53 transfection. Biomaterials 35: 3110-3120, 2014.

16. Wan C, Qian J, Li F and Li H: Ultrasound-targeted microbubble destruction enhances polyethylenimine-mediated gene transfection in vitro in human retinal pigment epithelial cells and in vivo in rat retina. Mol Med Rep 12: 2835-2841, 2015.

17. Sugano M, Negishi Y, Endo-Takahashi Y, Hamano N, Usui M, Suzuki R, Maruyama K, Aramaki Y and Yamamoto M: Gene delivery to periodontal tissue using Bubble liposomes and ultrasound. J Periodontal Res 49: 398-404, 2014.

18. Chen Z, Xie M, Wang X, Lv Q and Ding S: Efficient gene delivery to myocardium with ultrasound targeted microbubble destruction and polyethylenimine. J Huazhong Univ Sci Technolog Med Sci 28: 613-617, 2008

19. Zolochevska O, Xia X, Williams BJ, Ramsay A, Li S and Figueiredo ML: Sonoporation delivery of interleukin-27 gene therapy efficiently reduces prostate tumor cell growth in vivo. Hum Gene Ther 22: 1537-1550, 2011.
20. Tachibana $\mathrm{K}$ and Tachibana S: Transdermal delivery of insulin by ultrasonic vibration. J Pharm Pharmacol 43: 270-271, 1991.

21. Newman CM and Bettinger T: Gene therapy progress and prospects: Ultrasound for gene transfer. Gene Ther 14: 465-475, 2007.

22. Wang G, Zhuo Z, Xia H, Zhang Y, He Y, Tan W and Gao Y: Investigation into the impact of diagnostic ultrasound with microbubbles on the capillary permeability of rat hepatomas. Ultrasound Med Biol 39: 628-637, 2013.

23. Tomizawa M, Shinozaki F, Motoyoshi Y, Sugiyama T, Yamamoto S and Sueishi M: Sonoporation: Gene transfer using ultrasound. World J Methodol 3: 39-44, 2013.

24. Marentis TC, Kusler B, Yaralioglu GG, Liu S, Haeggström EO and Khuri-Yakub BT: Microfluidic sonicator for real-time disruption of eukaryotic cells and bacterial spores for DNA analysis. Ultrasound Med Biol 31: 1265-1277, 2005.

25. Bai WK, Wu ZH, Shen E, Zhang JZ and Hu B: The improvement of liposome-mediated transfection of pEGFP DNA into human prostate cancer cells by combining low-frequency and low-energy ultrasound with microbubbles. Oncol Rep 27: 475-480, 2012.

26. Livak KJ and Schmittgen TD: Analysis of relative gene expression data using real-time quantitative PCR and the 2(-Delta Delta C(T)) Method. Methods 25: 402-408, 2001.

27. Scott SL, Earle JD and Gumerlock PH: Functional p53 increases prostate cancer cell survival after exposure to fractionated doses of ionizing radiation. Cancer Res 63: 7190-7196, 2003.

28. Sicklick JK, Li YX, Jayaraman A, Kannangai R, Qi Y, Vivekanandan P, Ludlow JW, Owzar K, Chen W, Torbenson MS and Diehl AM: Dysregulation of the Hedgehog pathway in human hepatocarcinogenesis. Carcinogenesis 27: 748-757, 2006

29. Wang XB, Liu QH, Wang P, Zhang K, Tang W and Wang BL: Enhancement of apoptosis by sonodynamic therapy with protoporphyrin IX in isolate sarcoma 180 cells. Cancer Biother Radiopharm 23: 238-246, 2008.

30. Fang HY, Tsai KC, Cheng WH, Shieh MJ, Lou PJ, Lin WL and Chen WS: The effects of power on-off durations of pulsed ultrasound on the destruction of cancer cells. Int J Hyperthermia 23: 371-380, 2007.

31. Kodama T, Tomita Y,Koshiyama K and Blomley MJ: Transfection effect of microbubbles on cells in superposed ultrasound waves and behavior of cavitation bubble. Ultrasound Med Biol 32: 905-914, 2006.

32. Ecke TH, Schlechte HH, Hübsch A, Lenk SV, Schiemenz K, Rudolph BD and Miller K: TP53 mutation in prostate needle biopsies-comparison with patients follow-up. Anticancer Res 27: 4143-4148, 2007.

33. Gupta K, Thakur VS, Bhaskaran N, Nawab A, Babcook MA, Jackson MW and Gupta S: Green tea polyphenols induce p53-dependent and p53-independent apoptosis in prostate cancer cells through two distinct mechanisms. PLoS One 7: e52572, 2012.

34. Li X, Li Y, Hu J, Wang B, Zhao L, Ji K, Guo B, Yin D, Du Y, Kopecko DJ, et al: Plasmid-based E6-specific siRNA and co-expression of wild-type p53 suppresses the growth of cervical cancer in vitro and in vivo. Cancer Lett 335: 242-250, 2013.

35. Wang JF, Wu CJ, Zhang CM, Qiu QY and Zheng M: Ultrasound-mediated microbubble destruction facilitates gene transfection in rat C6 glioma cells. Mol Biol Rep 36: 1263-1267, 2009.

36. Manome $\mathrm{Y}$, Nakayama N, Nakayama $\mathrm{K}$ and Furuhata $\mathrm{H}$ : Insonation facilitates plasmid DNA transfection into the central nervous system and microbubbles enhance the effect. Ultrasound Med Biol 31: 693-702, 2005. 